\title{
APPLICATION OF THE INTERNET MARKET RESEARCH METHODS IN HOSPITALITY
}

\author{
ANDRLIC, B. \& BUDIC, H.
}

Abstract: This paper analysis the role of Internet market research in hospitality due to it's changing and complex environment. New aspects of consumer behavior and especially new technologies give rise to new or existing tourism growth markets. In order to examine this problem the following methods were used: analysis, synthesis, induction, deduction and online secondary research. Results showed that online market research methods improve the quality of e-marketing process in hospitality.

Key words: market research, methodology, internet, hospitality
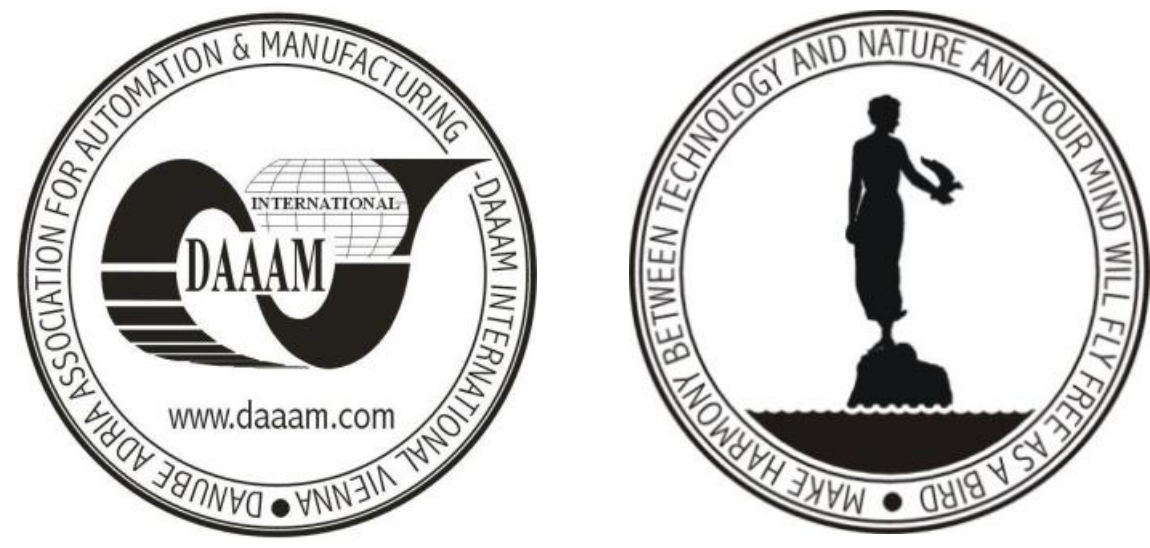

Authors' data: MSc Andrlic, B[erislav]; MSc Budic, H[rvoje], Polytechnic of Pozega , Vukovarska 17, 34000, Pozega, Croatia, bandrlic@vup.hr, hbudic@vup.hr

This Publication has to be referred as: Andrlic, B[erislav] \& Budic, $\mathrm{H}$ [rvoje] (2010). Application of the Internet Market Research Methods in Hospitality, Chapter 44 in DAAAM International Scientific Book 2010, pp. 497-508, B. Katalinic (Ed.), Published by DAAAM International, ISBN 978-3-901509-74-2, ISSN 1726-9687, Vienna, Austria

DOI: 10.2507/daaam.scibook.2010.44 
Andrlic, B. \& Budic, H.: Application of the Internet Market Research Methods in ...

\section{Introduction}

Business on the principles of marketing and modern management achievements implies a continuous activity at getting diverse information for decision - making in the hospitality industry (Vranešević, et al., 2004). The information is conceptual and hierarchical perspective, a broader term that is superior to data. As one of the fundamental forces of the modern developed marketing society, information has an attribute that does not have any other resource in economic development: it is inconsumable, using is not reduced. The aim of this paper is to determinate main market research methods in hospitality which is mentioned in previous researches. Specific goals of paper are focused on determinating advantages and disadvantages of online research methods. (Andrlic \& Budic, 2010)

\section{Process of market research}

Business on the principles of modern marketing and management achievements implies constant activity on getting different information for decision - making in hospitality industry. Conceptually and hierarchically speaking information is broader concept that is superior to data. As one of the main forces of the modern developed marketing, information has a feature that no other resource in economic development has: it is inalienable, the use of it does not decrease it's value. Information has another specific features: the format of information is multi - valued: it can be seen, pronounced, written, viewed, felt.

Analysis of marketing opportunities in exchange process in hospitality is based on market research. It is the essence and the core of decision making in marketing management. Any attempt to define the concept of an integrated market research must describe the role and the purpose which are set before the realization of a marketing plan. So, it is necessary to distinguish (Previsic \& Ozretic Dosen, 2004):

- cognitive (descriptive) task which sees and understands the problem and the existing and relevant datas and facts attached to it ;

- recognizable (diagnostic) task that involves gathering relevant information, their consideration, processing and explaining;

- anticipated (predictive) task which estimates the trends in the future, and which consequences of the actions can be expected.

Market research is a key element of marketing planning. It connects consumers, clients and the public with the company - information is used to identify and define market opportunities and problems, for creation, enhancement and evaluation of marketing activities, tracking marketing performance and improving knowledge of marketing as a process. Market research specifies the information needed to solve these problems; the method of data collection, manage and implement collecting data process, analyze results and communicate findings and their significance. 
Market information is a crucial element of effective marketing, it occurs as a result of a trend of a national and international marketing, transfer of consumer needs and desires, and transition from price competition to the competition of a different nature. Marketing management implies a need for constant flow of informations. In the area of exchange relations in marketing, there is a primarily expressed strong need from managers to exchange every day informations. There are many informations available to business decisions, but all are expected to have following common features (Marusic \& Vranesevic, 2001):

- punctuality,

- timeliness,

- reliability, to serve as a basis for decisions and actions.

The development of modern telecommunication and digital technology provides to marketing and to market research function a number of new features. In recent years technology has opened up unimagined possibilities of rapid collection of accurate and reliable informations. Recent organizational form for collecting data is called a marketing information system (MIS). It is organized as a series of procedures and methods that are continuous and planned, for collecting, analyzing and interpreting the datas, evaluating, protecting and distributing the informations which serves the business decision making. The definition refers to the three groups of essential components (Ruzic, et al, 2002):

- people and equipment for collecting the datas,

- procedures of collecting, analyzing, evaluating and distributing of collected datas,

- quantity and value of informations.

The collection of valid and reliable information is a variety of activities that are commonly known as a process of market research. This process consists of a logical sequence of procedures that should be implemented in order to efficiently come to reliable and valid information which helps in research process in the business market. The basis of the research process is based on a similar order as in performing any other tasks, and starts from the question of what to do, why, how, when, where and by whom. For ease of observation, and simple planning of activities, jobs are classified into certain groups, according to the principle of similarity. Below will be described the content of each phase of the research process. Stages of the process of market research, in all enterprises, including the hotels are (Marusic \& Vranesevic, 2001):

- definition of the problem and the objectives of the research,

- determination of the data sources and the type of the research,

- determination of the methods and the forms for data collection,

- determination of the sample and collecting the primary datas,

- data analysis and interpretation of the results,

- compiling the final report. 
In the process of market research, researchers at their disposal have two primary sources: primary and secondary sources. Selected sources of data must be in accordance with the defined research problem and must contain the necessary information that helps solving the problem. Secondary data are data that were collected before, in another research project, for different needs-assuming they are used for a research project carried out. When secondary datas are not available or sufficient for making marketing decisions, marketing research can be performed by gathering primary datas. Research and collection of this type of datas is implemented by conducting the field research with the help of two methods: testing and observation.

\section{Technological environment of business entities in the hospitality industry}

Modern marketing in hospitality is under constant influence of new technologies. Having in mind the specific characteristics of hospitality industry, the use of information technology in business is a condition without it can not function effectively in the market. In addition, we should respect the role of information technology as an essential factor in the success of the overall business of the company, given the following facts (Srica, 1999):

- the explosion of the knowledge and the information technology.

- speed, connectivity and added value are the main sources of sucess.

- informatics is a strategic business tool.

- briefing is becoming a fundamental business function.

- companies need information literacy.

- geo-strategic importance of informatics is growing.

Analyzing the previous facts and considering the role of technology in the hospitality, it is possible to notice the following perspectives of marketing:

- speed of gaining potential consumers becomes a key task, and their demands needs to be fullfiled in the shortest possible time,

- all must be connected with everything, hoteliers with hotel guests, products with services, deigners with future customers, i.e. all the former, current and potential guests mutually,

- the added value of the product and service must increase faster than the product and service itself,

- it is necessary to install the product in each service, and service in every product (hibryd welfare),

- the whole business should be managed in a real time, disposing all necessary informations at the time of their creation,

- by using the information technology the business costs are reduced,

- products and services should be offered interactively in a direct contact with potential guests, 
- all products and services should be individualized and adjusted to the individual guest,

- it is necessary to collect informations from each business transaction. These perspectives are applicable to the hotel marketing, which shows a high level of technology acceptance in relation to other economic activities. Using technology is therefore the competitive advantage of those hospitality companies if they use it properly. Information technology impact on business relationships change, permanently affects to the redefinition of hospitality industries and the relationship between the partners themselves, and in short-becoming the most important information resources in a hospitality business.

\section{Characteristics of Internet market research through the Internet}

The Internet is becoming an increasingly important source of secondary data, because it is the most cost-efficient medium for the research process. The best way to find information on the Internet is to know the exact web address URL (Uniform Resource Locator), that provides the desired information. To create greater awareness of the web address, the same is being promoted through offline channels (advertising on vehicles, billboards, business documents). The amount of web addresses, and the amount of informations on the Internet on a daily basis increases in high speed (206,675,938 web addresses in the world) (Netcraft, 2010). Some of those informations are free which facilitates their detection and availability. During the research of informations on the Internet attention should be given to the following questions:

- Is the information accurate?

- Is the information up-to-date?

- Is the information outdated?

- Which methods of sampling were used during their research?

In practice, there are many methods of primary researches which can be performed online (client satisfaction survey, survey feedback for new products in the market, etc.). Conducting primary online research starts with quality web site analysis, so some questions should be taken into consideration:

- Are the objectives clearly set up web page?

- Is the mission of the company clearly communicated?

- How is the effectiveness of offline promotion in relation to the number of visitors?

- What kind of changes could be done to improve the quality of services on the web?

- Is the site user friendly?

- How much the sales increased as a result of online contacts?

- How many visitors returns to the site? 
Andrlic, B. \& Budic, H.: Application of the Internet Market Research Methods in ...

- How the online sale is?

- What is the quality of website over the competition?

According to this questions, there are five specific categories of measurement proposed:

- Promotion channels analysis includes informations about getting consumers to a website. Key questions are: From which page did they come? Which offline adds they saw?

- Consumer behavior analysis on the web refers to most visited sections and the time spent on the site, which suggests opportunities for modifying the structure and the content of the page.

- Satisfaction rating visitors analysis evaluates the level of perceived quality of online service, such as the number of answered e-mail questions.There, it is possible to use tools such as Gomez (www.gomez.com) for comparing (benchmark) with xsa competing sites.

- Online sales revenue analysis measure the relation between the number of those who have left the site without purchasing regarding to those who have concluded the swap process online.

\section{Application of research methods for hospitality market}

Methods which are commonly conducted in online researches in hospitality industry are (George, 2002):

- Specialized software

- Web registration

- Questionnaire

- Online focus groups

- Computer Kiosk-Based Interviewing

- Internet panels

- Cookies

- Mystery shopping.

Specialized software tools are used to measure the effectiveness of web sites (web analytics). Such tools are available for applying via the Web in a free versions or in a payment. There are two main technological approaches to collecting data for web analytics. The first method, the analysis of $\log$ files, works in a way to peruse the $\log$ files in which the server records all transactions to extract the data. Page tagging is the second method, which is used by Java Script on every page which is followed to inform the third party server when the page is loaded in web browser (Ružić; Biloš \& Turkalj, 2009). As an examples of that kind of software tools it is possible to specify the Google Analytics and the Hitbox. Google Analytics is a web analytics which provide detailed attendance website and its marketing effectiveness. The tool 
is free and very easy to use and has gained wide application in the tourist-catering practice. Tool presents a number of variables, the number of new visitors (unique visitor), visitors who come back to the site (returning visitor), the most popular feature on the site, visitations of the site and length of each section, segmentation of users, etc. Another important feature of this tool is the option of monitoring results in a relation to it's marketing objectives. It provides the e-marketers the important results, which are implemented furthermore in a new marketing strategies on the Internet or they are compared with the leading companies in practice (benchmarking). As well as previously explained tool, Hitbox also belongs to a category of e-products and it is applicable in all industrial sectors for the monitoring of the effectinevess of the web site.

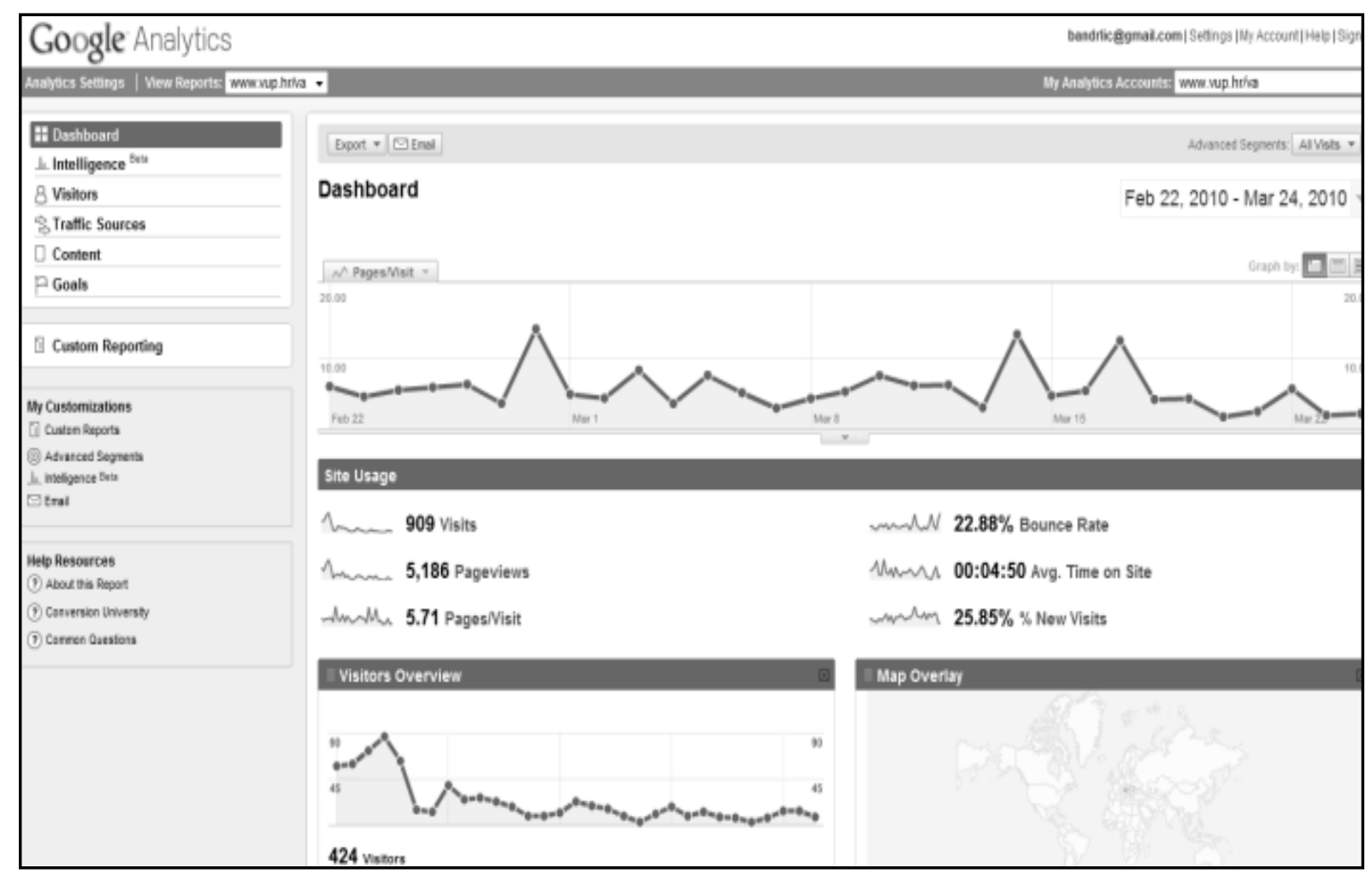

Fig. 1. Google Analytics tool

The questionnaire is the basic instrument of market research. It consists a series of questions asked to the respondent via the Internet, and the space for answers which are typed and marked by click by the respondent. Carefully compiled questionnaire is essential for the success of any research. Questions must be prepared to come up with informations which are set out as targets of a specific research study. Questions must be set up clearly, understandable and geared to specific goals.

Researchers must define the objectives before they attempt to put together a questionnaire, because the objectives determines the content of each question and the level of details. Usually there are three types of questions: open questions, dichotomous and multiple choice questions. In preparing the questionnaire the scales are used as a measuring tool to determine the quantitative indicators of research. Tools for creating and conducting surveys are very simple to use, for example, 
www.freeonlinesurveys.com, www.surveyshare.com / forms / questionnaire.html, etc. They provide the possibility of creating the questions, collecting the datas, analyzing the results and printing the final reports. Recommendation which is necessary to take into consideration is the length of the survey, because, if the survey is too long, it can happen non-response.

In order to identify visitors to the hotel company can apply the technique of web registration. Visitors to this case, the company makes its information voluntarily when registering, and they are usually full name, age, gender, place of residence, education, and other contact information.

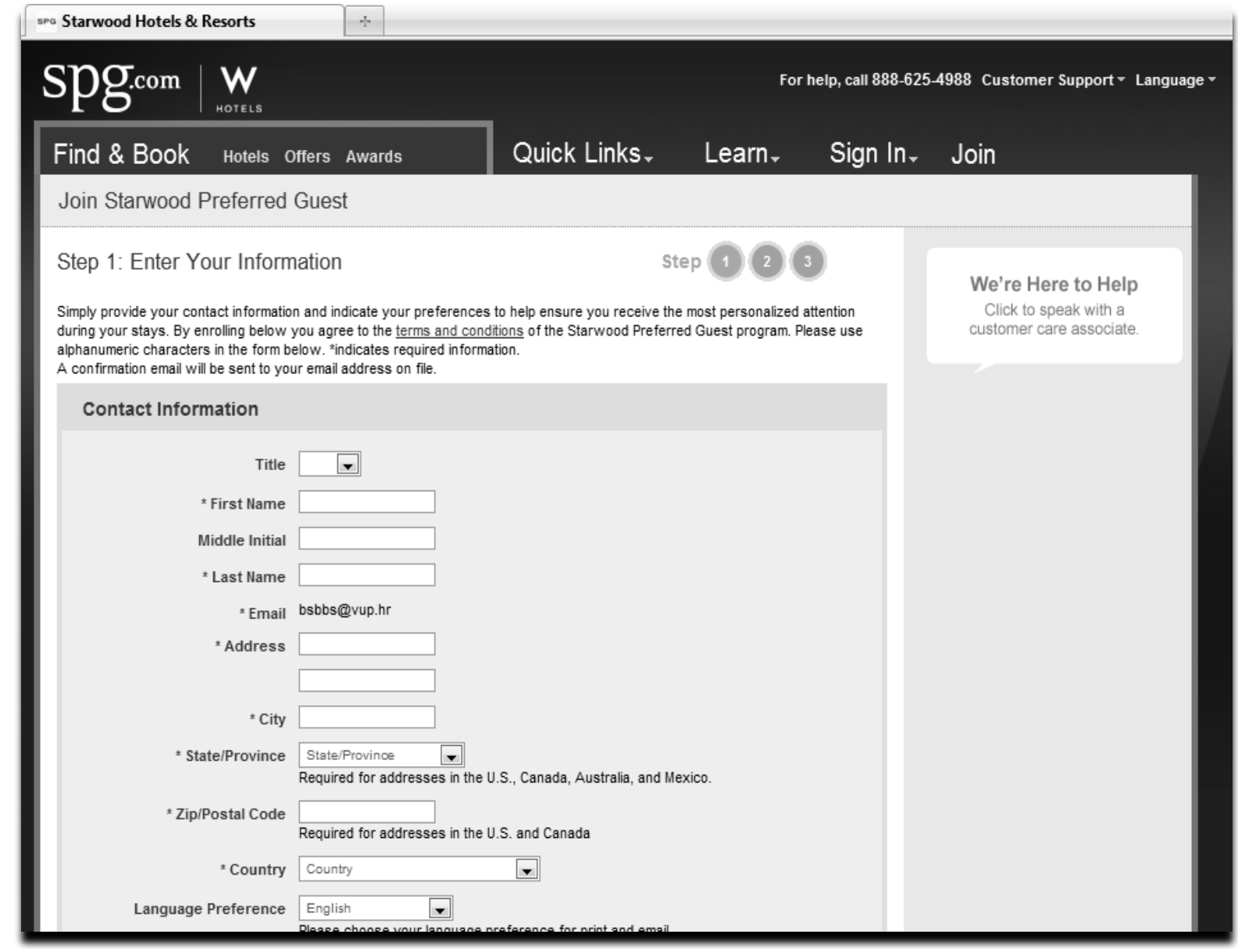

Fig. 2. Web registration ih hospitality

Using the obtain datas hoteliers can easily detect the segment of potential clients, and also with their approval send them a variety of promotional offers, questionnaires, informations and news by mail or e-mail. Email is "push technology". Just like telemarketing, door-to-door, and direct mailing, e-mail marketing pushes your message to prospective and existing customers, rather than relying on customers to seek you out first. (Elley \& Tilley, 2009)

Usually the three types of questions are used: open, dichotomous and multiple choice questions. In preparing the questionnaire we use scales which serve as a measuring tool in determination of the quantity indicators of the research. Specifically, the scales can be distinguished as: (Dibb, et al, 1995): 
- nominal (distincional); which performs classification or assorting giving only the labels which indicate the type of appearrance and nothing else,

- ordinal (series); which allows measuring the phenomena in terms of whether and which is presented more by the measured variable, and thus allows the ranking of responses,

- interval (distancable) ; enable a quantitative comparison between the values of certain types of phenomena,

- in ratio (rooted); which represents symbiosis in terms of features previously mentioned scales ("the most perfect" scale).

Questionnaires which are distributed via e-mail or web site are quick to fill, cheap, and cover wide geographical area. Datas can be easily analyzed. There are two basic ways of conducting that research:

- by sending an e-mail message which contains a link to the online questionnaire on a particular web page,

- by using pop-up window on the web page through which we can enter the questionnaire located on the web page.

Tools for preparing and conducting surveys are very simple to use, for example, www.freeonlinesurveys.com, www.surveyshare.com / forms / questionnaire.html, etc. They provide the ability to create questions, collect data, analyze results and printing of final report. Recommendations that must be taken into consideration is the length of the survey, as in the case of the survey too long to happen non-response due to lack of time respondents.

Online focus groups are forms of testing which are still in development phase, while in countries like the U.S. they are already widely spread.Such kind of a discussion is organized by the company, and by the Internet the samples of consumers are gathered in a real time in which they communicate and answer the questions.This is like brainstorming in which people generate ideas, while the process is led by the moderator. Recently, the social networks are used in which profiles the consumers of similar interests are gathered, which spread experiences about products and services "click by click". (Zarrella, 2010)

Computer Kiosk-Based Interviewing is an innovative form of market research supported by digital technology. It's aim is to explore sale's experience, and it is usually carried out within the major shopping centers.

Internet panel represents a permanent representative sample of households that are continually built and maintained. Such a database is a technologically advanced form of connecting virtually unlimited number of characteristics or variables in a dynamic system. The concept of databases is known for ages. However, now it includes high technology which enables hotels to identify, differentiate, interact and personalize relationships with large number of customers while increasing the efficiency of those 
Andrlic, B. \& Budic, H.: Application of the Internet Market Research Methods in ...

systems (Stone \& Jacobs, 2001). Trends that have led to the development and increase of the intensity of use of databases and their need for technological development are:

- market fragmentation,

- more educated consumers,

- all major emphasis on CRM and consumer services,

- changes in the media and technological advances,

- changes in the distribution,

- demographic and psychographic trends,

- integration of business functions in hotel companies.

A cookie is an information which web server stores on the web which writes it in a text file on your computer. This usually happens during the first visiting, or in filling out various forms and login to the websites. This text file (cookie) your browser (Internet Explorer, Firefox) sends the web server every time you ask his website. A cookie contains informations about the user and it's main purpose is to present options from the web site personalized to him.

Mystery Shopping is a technique that is increasingly used in e-marketing. As an example it is possible to specify www.emysteryshopper.com.Secret e-shoppers have a task to test the selected web page through this: utility, updating, response time and impact on the brand.

Except these techniques, there are traditional techniques of market research which in greater or smaller measure use contemporary tehnologies.

Application of appropriate research methods depends primarily on the problem under investigation. Testing can be done in four basic ways of communicating with the subjects: a personal study, postal questionnaires, telephone testing and testing by computer (Vranesevic et al, 2004):

- CATI (Computer Assisted Telefon Interveiwing) or WATS (Wide Area Telecommunications Service); telephone survey with a computer application in which the computer program selects the name and telephone number of respondents. According to the established telephone contact, interviewer conducts survey and enters responses directly into a computer during research.

- $\quad$ CAPI (Computer Assisted Personal Interveiwing); the questionnaires are programmed in software. The interviewer receives a laptop and conducts computer-steered interviews at the respondent's homes, at some central point (e.g. in a shopping centre), or at the respondent's workplaces, etc.

- CSAQ (Computerized Self-Administered Questionnaires), or CII (Computer Interactive Interveiwing); method of collecting survey data that takes advantage of computer technology to create an instrument (the 
questionnaire) that allows respondents to complete the survey with little or no other human assistance.

- $\quad$ CAWI (Computer Assisted Web Interveiwing) ; questionnaire appears in the browser as a web-page that respondents can reach in different ways depending on the sample design. The answers for the questionnaire get immediately to the main server so the data collection and the results can be tracked continuously. Even multimedia materials (pictures, audio or music files) can be integrated into the questionnaire.

In addition, basic information that hotel company can collect about guests, depending on the characteristics of information, can be divided into: (Ryan, 2001):

- contact data (name, address, phone,e-mail)

- demographic data

- psychographic data

- previous purchases

- history of contact and communication with the consumer.

In order to adequately manage the information it is necessary to implement a CRM system in hotels through the following phases (Forrest, 2003):

- finding information

- information exchange

- information selection

- presentation and use of information

- information management

- personalization.

Most of the hotels have introduced the practice methods of collecting data on the "opt-in" and "opt-out" approach. With the "opt-out" approach datas are collected without guest's knowledge, but allows them to ban use of informations by the hotel company. While this approach gives consumers a choice to use their information, the big problem is the fact that hotels already have those datas and that consumers depend only on their good will to respect the desire of consumers for not using their information.

Therefore, to ensure consumer confidence, hotel companies are increasingly using the "opt-in" approach which works on the permission and goodwill of consumers which gives informations to the hotels, which is later used in the process of making marketing decisions.

\section{Conclusion}

Online market research is a key element of the marketing information in hospitality. It connects consumers, clients and the public with the company using the 
Andrlic, B. \& Budic, H.: Application of the Internet Market Research Methods in ...

information. Marketing opportunities analysis, in which the swap process is carried out on the hospitality market is based on market research. It is the essence and the core of decision making system in marketing management. Any attempt to a comprehensive definition of market research must describe the role and the purpose in which the research is set as a part of marketing plan.

\section{References}

Andrlic, B \& Budic, H. (2010). Possibilities of tourism market research via the Internet, Annals of DAAAM for 2010 \& Proceedings of the $21^{\text {st }}$ International DAAAM Symposium, Zadar, Croatia, p. 79

Dibb S., Simkin L., Pride W. M. \& Ferrell, O.C. (1995). Marketing, Mate, Zagreb,

Elley, B \&Tilley, S. (2009). Online Marketing Inside Out, SitePoint Pty. Ltd, Collingwood

Forrest, E. (2003). Internet Marketing Intelligence - Research Tools, Techniques, and Resources, McGraw Hill Irwin, Boston

George, J.F. (2002). Influences on the intent to make Internet purchases, Internet Research: Electronic Networking Applications and Policy, Vol.12., No.2. p. 165

Harris, L \& Dennis, C. (2008). Marketing the e-Business, Routledge, Abingdon

Marusic, M. \& Vranesevic, T. (2001). Market research, Adverta, Zagreb

Previšic J. \& Ozretic Došen Đ.(2004) Marketing, Adverta, Zagreb

Ruzic, D., Tomcic, Z. \& Turkalj, Z (2002). Marketing relationships- organization and application, Sveučilište Josipa Jurja Strossmayera u Osijeku, Ekonomski fakultet Osijek, Osijek

Ruzic, D., Bilos, A. \& Turkalj, D. (2009). e - Marketing Sveučilište J.J. Strossmayera, Ekonomski fakultet Osijek, Osijek

Ryan, C. (2001). High-Performance Interactive Marketing - New Techniques and Technologies for Winning and Keeping Customers, Racom Communications, Evanston

Srica, V (1999). Informatics for managers MEP Consvet, Zagreb

Stone, B. \& Jacobs, R. (2001). Successful Direct Marketing Methods, McGraw Hill, New York

Vranešević T., Vignali C. \& Vrontis D. (2004). Strategic marketing management, Accent, Zagreb

Zarrella, D. (2010).The Social Media Marketing Book, O'Reilly Media, Inc., Sebastopol

***(2010)http://news.netcraft.com/archives/web_server_survey.html, Web server survey, Accessed on: 2010-03-25 